\title{
The Importance of Confirming Citizens' Expectations in e-Government
}

\author{
Daniel Belanche ${ }^{1}$, Luis V. Casaló ${ }^{2}$, and Carlos Flavián ${ }^{1}$ \\ ${ }^{1}$ Universidad de Zaragoza, Faculty of Economics, Gran Vía 2, 50.005, Zaragoza, Spain \\ ${ }^{2}$ Universidad de Zaragoza, School of Business Studies, Ronda Misericordia 1, 22.001, \\ Huesca, Spain \\ \{Belan, lcasalo, cflavian\}@unizar.es
}

\begin{abstract}
Satisfying consumer needs is a core principle of marketing. However, in the context of e-government, most studies up to now have focused on adoption models such as Technology Acceptance Model or Theory of Planned Behavior, forgetting citizens' needs, demands or expectations. To overcome this, in this work we analyze how confirmation of citizens' expectations may influence citizens' perceptions and behavioral intentions in the e-government context. As well, due to its great influence on consumer behavior, we investigate some factors that may enhance citizens' intention to recommend online public services. Data from 232 citizens reveal that confirmation of expectations and perceived usefulness effectively predicts citizen intention to use online public services. As well, positive word of mouth among citizens is positively affected by confirmation of expectations and intention to use these services. Finally, confirmation of expectations confirms its importance by influencing perceived usefulness too.
\end{abstract}

Keywords: E-government, intention to use, confirmation of expectations, WOM, perceived usefulness.

\section{Introduction}

In the last years, governments have increased the offer of public services on the Internet. For example, in Spain the law 11/2007 (Ley 11/2007, de 22 de junio, de acceso electrónico de los ciudadanos a los Servicios Públicos) acknowledges the citizens' right to interact with the Public Administration in an online manner in order to obtain information, make questions or carry out transactions among other tasks in the citizen-government relationship. However, most of these new electronic services offered by governments are still in a starting point and remain unfamiliar for most citizens. The acceptance of these e-services not only by pioneers, but also by follower citizens may allow achieving a critical mass of users that guarantees the success of these egovernment initiatives.

Despite widespread acceptance of the importance of e-government initiatives (e.g. Belanche et al. 2009), there is a relative paucity of knowledge about the determinants of citizens' intention to use online public services. Indeed, up to now almost all 
studies in this regard have focused on well-known adoption models such as the Technology Acceptance Model or the Theory of Planned Behavior (e.g. Wu and Chen 2005). Therefore, little consensus exists about what else motivates people to use these online public services. As well, as far as know, there is no empirical assessment of the antecedents of citizens intention to promote these e-government initiatives, which in turn might be one of the most powerful forces in persuading fellow citizens to use these services. Thus, both theoretically and managerially, we require a more in-depth understanding of citizen behavior in the e-government context.

This research contributes to previous literature by addressing two critical issues. First, we examine the role that confirmation of expectations may have on citizens' perceptions and behavioral intentions. It is important to note that citizens have different roles in the complex government-citizen relationship, being one of these the role as a consumer of public services (Steyaert 2000). Sometimes these services are compulsory, but in other cases their use is volitional; so to provide efficient services, citizen needs and requirements should be taken into account. Therefore, the confirmation of citizens' expectations may provide a useful explanation of post-usage behaviors in the e-government context. This variable reflects the degree to which expectations generated on previous occasions have been met, resulting from a person's perception that the benefits received are equal to (or greater than) the expected benefits, increasing the perceived usefulness of using the online public service. As well, met expectations may lead users to feel satisfied and motivated to use repeatedly and promote these online public services. However, to the best of our knowledge, this role of confirmation of expectations has not been analyzed in this context.

Second, due to its great influence on individuals' choices (Chung and Darke 2006), we investigate some factors that may enhance citizens' intention to recommend online public services. In particular, we investigate confirmation of expectations, perceived usefulness, and intention to use the online public service as potential determinants of positive word of mouth [WOM hereafter] among citizens. The reason behind this may be found in the fact that an individual may recommend a product/service if s/he perceives that it is useful or has some kind of affective commitment towards it (these affective ties may be caused by a positive evaluation confirming previous expectations). As well, if citizens have the intention to use online public services, it is likely that they perceive a greater value when using them. In response to that, citizens may also be motivated to promote these services to fellow citizens.

Therefore, this work is structured as follows: First, we formulate the study hypotheses. Second, we describe the data collection process, as well as the methodology we employ. Then, we present the results of the research. Finally, we discuss the main findings, conclusions and managerial implications of the work.

\section{Formulation of Hypotheses}

First, we expect a positive effect of confirmation of expectations on perceived usefulness. This is explained by the fact that initially, although the lack of experience involves uncertainty, citizens have some perceptions about the level of usefulness of the service. If they finally use it and general expectations about service's performance are confirmed, citizens will perceive higher levels of positive website attributes (such us 
usefulness) than previously thought. Then, citizens may use their experience as a basis to form more precise perceptions and adjust their expectations. This reasoning is supported by the Cognitive Dissonance Theory (Festinger 1957), which suggests that rational individuals try to eliminate the dissonance between pre-acceptance thoughts and actual performance evidences by modifying previous expectations in order to be more consistent with reality. Broadly speaking, in our case, confirmation of expectations should serve to increase perceived usefulness of using an online public service, while negative disconfirmation should reduce perceived usefulness. Indeed, this link has been proved in the Information System Continuance Model developed by Bhattacherjee (2001). Therefore, we propose our first hypothesis:

H1: Confirmation of expectations has a positive effect on the perceived usefulness of using an online public service.

In addition, the intention to use an information system is primarily determined by consumer satisfaction with prior usage experience (Bhattacherjee 2001). More specifically, satisfaction reflects that benefits derived from using a system are, at least, equal to the expected ones. Thus, if these expectations are met, the individual will be motivated to continue using the system. To be precise, expectations provide the baseline level against which perceived performance is compared in order to determine the consumer evaluative response. In this sense, confirmation of expectations implies the realization of the expected benefits, while disconfirmation leads to dissatisfaction since it denotes failure to achieve expectation (Bhattacherjee 2001). Therefore, in our context of analysis, we may expect that confirmation of expectations motivates citizens to continue using an online public service. Bearing in mind these considerations, we propose the second hypothesis:

H2: Confirmation of expectations has a positive effect on the intention to use an online public service.

Traditionally, several authors have stated that satisfaction leads to an increased probability that consumers will talk in a favorable manner about an organization and recommend the firm to other customers (e.g. Dolen et al. 2007). Broadly speaking, due to the fact that satisfied consumers confirm their expectations and demands when using an organization's products/services, these customers may be effective promoters of the organization (Dolen et al. 2007). Therefore, it seems reasonable to think that citizens that confirm their expectations when using an online public service will be more likely to promote the service, thanks to positive comments about it made to fellow citizens, rather than those that experience a negative disconfirmation. Bearing these considerations in mind, we propose the following hypothesis:

H3: Confirmation of expectations has a positive effect on citizens' positive WOM.

In turn, the Technology Acceptance Model (e.g. Davis et al. 1989) proposes that perceived usefulness not only influences the acceptance intention indirectly (through attitude), but it also has a direct effect on intention to use. Indeed, individuals also form their behavioral intentions according to the expected productivity associated to that behavior (Davis 1989). For instance, Vroom (1964) noted that good performance within an organizational context is usually rewarded by monetary gains or promotions. Therefore, in this context, information systems may be seen as means to reach that end, so that the adoption of information systems among workers may be enhanced. Analogously, focusing on our context of analysis, online public services may be seen as a worthwhile mean in order to carry out regular citizen's task by saving 
time and costs. Thus, the intention to participate in this kind of citizen-government relation may be enhanced due to its usefulness. Consequently, we propose the following hypothesis:

H4: Perceived usefulness of using an online public service has a positive effect on the intention to use that service.

Following East et al. (2007), positive WOM is not only caused by consumer satisfaction, but many other stimuli may motivate WOM communications. Among these, WOM most usually appears when the receiver of the communication has a special need and asks for specific information (Mangold et al. 1999). In this situation, the communicator will likely recommend the most useful option according to the receivers' needs. Thus, it is reasonable to think that, in the context of e-government, citizens will more likely recommend the use of online public services if these services are perceived as useful and valuable. Indeed, Mangold et al. (1999) found that value and quality -two concepts very close to usefulness- are the product/service attributes that stimulate most WOM communication. Therefore, we propose the following hypothesis:

H5: Perceived usefulness of using an online public service has a positive effect on citizens' positive WOM.

Finally, the intention to use a product/service reflects favorable consumer attitudes towards it and the organization that provides it (e.g. Evanschitzky et al. 2006). In this respect, one of the consumer behaviors that might benefit the organization derived from this favorable disposition is the development of positive WOM and recommendation (Hallowell 1996) by emphasizing the main attributes of the organization products and services. This is motivated by the fact that the intention to use the service is the result of the individual's beliefs that the quantity of value received from consuming a product or service is greater than the value of non-consuming (Hallowell 1996). Thus, in response to this greater value obtained, the individual is motivated to use the service again and to promote it by, for instance, positive WOM behaviors. Indeed, this fact will reinforce the suitability of the decision to use that service and enhance the idea of being a good citizen that try to spread the benefits of a public resource among fellow citizens in his/her community. Therefore, taking these considerations into account, we propose in our last hypothesis that intention to use an online public service may favor the development of positive WOM among citizens:

H6: The intention to use an online public service has a positive effect on citizens' positive WOM.

\section{Data Collection}

We collected the data for this study from a Web survey of Spanish-speaking citizens. This method is consistent with common research practices online (e.g., Steenkamp and Geyskens 2006). To obtain responses, we included a link on a Spanish Governmental Agency which collaborated in the research promotion. When potential interviewees entered the study Web site, they found the research questionnaire and additional information about the research project. We finally collected 232 valid questionnaires (after eliminating atypical cases, repeated responses, and incomplete questionnaires). 
The study subjects chose the online public service they analyzed (among those offered in the collaborating agency), because we work to assess citizens' behaviors regardless of the specific characteristics of the public service. We simply required the respondents to have used the online public service selected at least once in the last year. Respondents then answered several questions about their levels of confirmation of expectations, and perceived usefulness of the online public service, as well as their intentions to use the system again and recommend it to fellow citizens. These measures use a seven-point Likert type response format, and respondents rated them from 1 ("completely disagree") to 7 ("completely agree").

\section{Measures Validation}

An in-depth review of the relevant literature concerning relationship marketing and emarketing was developed to propose an initial set of items to measure the latent constructs. This review helped guarantee the content validity of the scales. We also tested face validity -the degree that respondents judge that the items are appropriate to the targeted construct- through a variation of the Zaichkowsky method (1985). Following this method, each item was qualified by a panel of experts as "clearly representative", "somewhat representative" or "not representative of the construct of interest". Finally, items were retained if a high level of consensus was observed among the experts (Lichtenstein et al. 1990).

The first step in the process of measures validation was an exploratory analysis of reliability and dimensionality. In this sense, the Cronbach's alpha indicator considering a minimum value of .7 (Nunnally 1978)-, the item-total correlation -considering a minimum value of .3 (Nurosis 1993)-, and principal components analysis were used to assess the initial reliability and dimensionality of the scales. All items were adjusted to the required levels and only one factor was extracted from each scale: confirmation of expectations, perceived usefulness, intention to use and positive WOM.

In order to confirm the dimensional structure of the scales, we used the Confirmatory Factor Analysis. For these tasks, the statistical software EQS v.6.1 was employed and we used Robust Maximum Likelihood as an estimation method. The criteria proposed by Jöreskog and Sörbom (1993) were followed in order to depurate the scales. Following these recommendations, we obtained acceptable levels of convergence, $\mathrm{R}^{2}$ and model fit (Chi-square $=46.861,29$ d.f., $\mathrm{p}=.01923$; Satorra-Bentler Scaled Chisquare $=30.1946,29$ d.f., $p=.40434$; Bentler-Bonett Normed Fit Index =.98; BentlerBonett Nonnormed Fit Index =.99; Comparative Fit Index (CFI) =.99; Bollen (IFI) Fit Index =.99; Root Mean Sq. Error of App. (RMESA) $=.013 ; 90 \%$ Confidence Interval of RMESA $(.000, .052))$.

Additionally, we used the composite reliability indicator to asses construct reliability (Jöreskog 1971). We obtained values above .65 (see table 1), exceeding the benchmarks that are suggested as acceptable (Steenkamp and Geyskens 2006). Finally, convergent validity, which indicates whether the items that compose a scale converge on one construct, was tested by checking that the factor loadings of the confirmatory model were statistically significant (level of .01) and higher than .5 
points (Steenkamp and Geyskens 2006). As well, we used the Average Variance Extracted (AVE) to contrast the convergent validity and obtained acceptable values greater than .5, which implies that items that compose a determined scale contain less than $50 \%$ error variance and converge on only one construct (Fornell and Larcker 1981). On the other hand, discriminant validity, which reveals whether a determined construct is significantly distinct from other constructs that are not theoretically related to it, was tested by comparing the square root of the AVE with the correlations among constructs. That is, we checked that the construct shares more variance with its own measures than the variance it shares with the other constructs in the model (Wiertz and De Ruyter 2007). The results show acceptable levels of discriminant validity since all diagonal values exceed the inter-construct correlations.

\section{Results}

To test the hypotheses, we developed a structural equation model, which offers the results in Figure 1. All hypotheses are supported at the .01 level, unless hypothesis 5 which is not confirmed. As well, model fit achieves acceptable values (Chi-square = 46.861, 29 d.f., $p=.01923$; Satorra-Bentler Scaled Chi-square = 30.1872, 29 d.f., $p=$ .40470; Bentler-Bonett Normed Fit Index =.98; Bentler-Bonett Nonnormed Fit Index =.99; Comparative Fit Index (CFI) =.99; Bollen (IFI) Fit Index =.99; Root Mean Sq. Error of App. (RMESA) =.013; 90\% Confidence Interval of RMESA (.000, .052); normed Chi-square $=1.6159$ ).

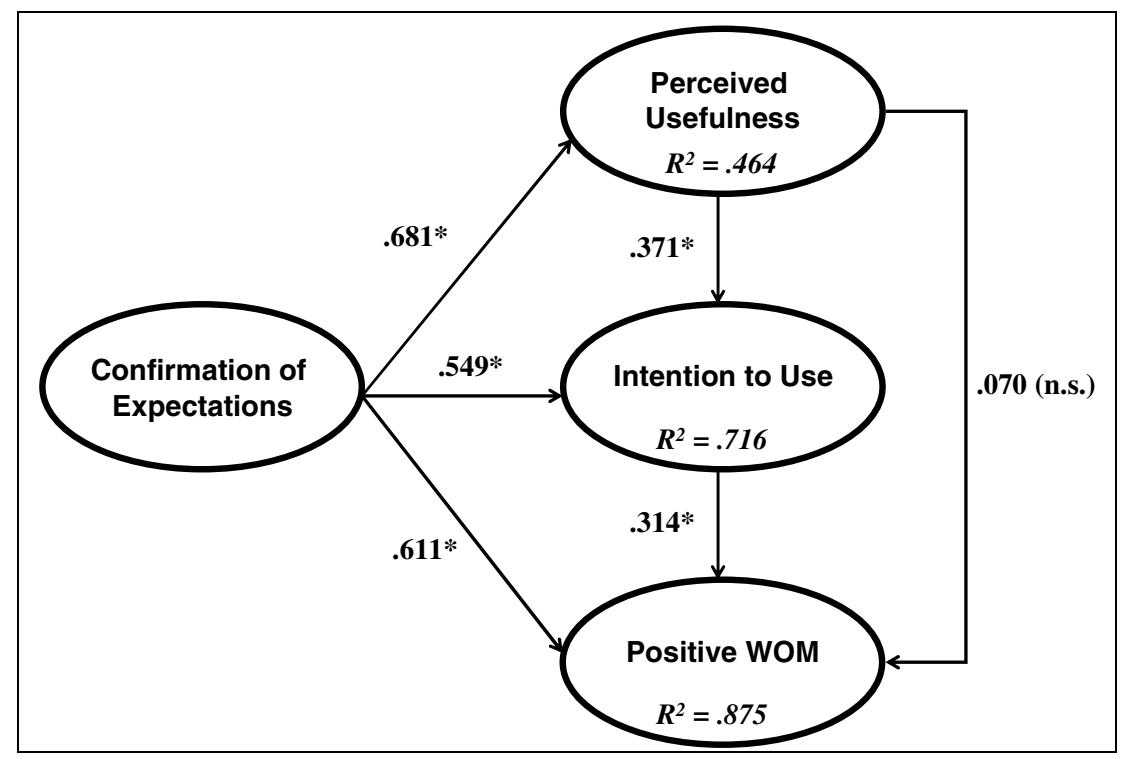

Fig. 1. Structural equation model: Standardized solution. Note: “*”Coefficients are significant at .01 level; (n.s.) coefficients are non-significant. 
Firstly, in accordance with standardized coefficients, it has been proved that confirmation of expectations positively affects perceived usefulness of an online public service $(\lambda=.681, p<.01)$, intention to use that service $(\lambda=.549, p<.01)$, and intention to recommend it -positive WOM- $(\lambda=.611, p<.01)$, in support of hypotheses 1 , 2 and 3, respectively. Secondly, perceived usefulness also shows a positive effect on the intention to use an online public service $(\beta=.371, p<.01)$, confirming hypotheses 4 . Finally, positive WOM among citizens is positively affected by intention to use an online public service $(\beta=.314, p<.01)$, but contrary to expected it is not significantly influenced by perceived usefulness of the service $(\beta=.070, p>.1)$. As a result, we accept hypothesis 6 , but hypothesis 5 could not be confirmed.

We further remark that this simple model can partially explain the endogenous variables of the study: perceived usefulness of using an online public service $\left(\mathrm{R}^{2}=\right.$ $.464)$, citizen intention to use that service $\left(R^{2}=.716\right)$ and, especially, citizen intention to recommend the use of the system -positive WOM- $\left(\mathrm{R}^{2}=.875\right)$.

\section{Discussion}

The results of this research have helped to remedy, to a certain extent, the lack of empirical studies that analyze: (1) citizens' motivations to use online public services (apart from the adoption models used up to now), and (2) the positive WOM development in the e-government context. Indeed, the analysis of WOM in this context is especially relevant since WOM is more important and influential in the services context because of their intangibility (Murray and Schlacter 1990). Thus, citizens may appreciate WOM because in this situation fellow citizens are seen as more objective and reliable than other information sources.

Specifically, in this study, we first have seen that intention to use online public services is determined by both confirmation of expectations and perceived usefulness. The effect of perceived usefulness on intention to use is coherent with previous applications of Technology Acceptance Model to the e-government context (e.g. Wu and Chen 2005). As well, the positive influence of confirmation of expectations is also in line with previous research in other contexts, since it has been widely used to explain post-usage behaviors such as intention to use again a product/service (e.g. Oliver 1980). In addition, in line with the Information System Continuance Model (Bhattacherjee 2001), perceived usefulness is influenced by confirmation of expectations, which in turn may also have an indirect effect on intention to use through perceived usefulness. As a result, the citizen's affective state derived from the confirmation of his/her expectations seems to have a deeper impact in developing citizen behavioral intentions, which might be considered as a first contribution of this study.

Secondly, positive WOM is mainly influenced by confirmation of expectations and, in a lesser extent, by the intention to use online public services. On the other hand, the direct effect of perceived usefulness seems to be non-significant. Although these results are quite surprising, we consider they are in line with previous findings in the e-commerce context. Indeed, Casaló et al. (2008) already found that, rather than individual beliefs about a service, affective feelings are the strongest precursor of positive WOM in the e-banking business. In our case, this affective state arises from the confirmation of citizens' expectations; that is, from satisfying citizens' demands. 
To sum up, we may conclude that, in the context of e-government, the confirmation of expectations directly affects citizens' behavioral intentions, in terms of preference for future use of online public services and recommendation to fellow citizens, which may therefore affect the probability of e-government success in a positive way. Therefore, this research offers several alternatives to increase the citizens' intentions to both use and recommend online public services, so that governments can develop and implement e-government initiatives more easily.

1. Firstly, governments should try to maximize the satisfaction of their citizens by confirming their expectations when using online public services. Customer satisfaction will be generated if the customer's expectations about the relationship are met. Therefore, governments should try to identify the needs of their citizens (e.g. in terms of services offered, design of the website, etc.) in order to offer them what they want in an efficient way. Thus, confirming citizens' expectations will lead to satisfied citizens that will be motivated to continue using these online services. In addition, satisfying customers may serve to avoid the negative WOM generated by dissatisfied customers. This fact is especially relevant since negative actions have a more intense impact on the individual than positive ones. However, it is important to note that the process of satisfying citizens is not an easy task; there is a wide spectrum of citizens with different abilities and needs, so that satisfying all of them may be a difficult issue. In this way, we recommend to prioritize ease-of-use in website design, promoting access to these services (e.g. by offering free wifi zones in public buildings and spaces, etc.) in order to overcome the access barriers that exist in some groups of the population, and constantly analyze the evolution of citizens' needs and demands.

2. Secondly, perceived usefulness has revealed as a crucial aspect in forming citizens' intention to use online public services. The degree of perceived usefulness can also be improved through some strategies. However, online public services may be considered as experience goods so their usefulness is difficult to perceive until they have been used. To overcome this obstacle, it is necessary to promote the test and the benefits that citizens can obtain by using them (e.g. saving time and cost, less paper waste -ecological concern-, etc.). To do that, the Public Administration can contact citizens directly (e.g. by post mail, e-mail, etc.) or conduct promotional campaigns in mass media in order to explain these benefits in more detail. In this way, it will be possible to create an external influence that increases citizen's perceptions that it is useful and trendy to use online public services.

Thus, improving the confirmation of citizens' expectations and the perceived usefulness of online public services will promote citizens' intentions to use and recommend online public services. As a consequence, the success of e-government initiatives will be more likely.

\section{References}

1. Belanche, D., Casaló, L.V., Flavián, C.: Citizen adoption of e-government based on TAM and TPB models. In: VIII International Congress on Public and Non Profit Marketing, Valencia (2009) 
2. Wu, I.L., Chen, J.L.: An extension of Trust and TAM model with TPB in the initial adoption of on-line tax: An empirical study. Int. J. Hum.-Comput. Stud. 62, 784-808 (2005)

3. Steyaert, J.: Local governments online and the role of the residents. Government shop versus electronic Community. Soc. Sci. Comput. Rev. 18(1), 3-18 (2000)

4. Chung, C.M.Y., Darke, P.R.: The consumer as advocate: Self-relevance, culture and wordof-mouth. Mark. Lett. 17, 269-279 (2006)

5. Festinger, L.A.: A Theory of Cognitive Dissonance. Stanford University Press, Stanford (1957)

6. Bhattacherjee, A.: Understanding Information Systems Continuance: An Expectation/Confirmation Model. MIS. Q. 25(3), 351-370 (2001)

7. Dolen, W.M., van Dhabolkar, P.A., De Ruyter, K.: Satisfaction with Online Commercial Group Chat: The Influence of Perceived Technology Attributes, Chat Group Characteristics, and Advisor Communication Style. J. Retail. 83(3), 339-358 (2007)

8. Davis, F.D., Bagozzi, R.P., Warshaw, P.R.: User Acceptance of Computer Technology: A Comparison of Two Theoretical Models. Manag. Sci. 35(8), 982-1003 (1989)

9. Davis, F.: Perceived Usefulness, Perceived Ease of Use and User Acceptance of Information Technology. MIS. Q. 13(3), 319-340 (1989)

10. Vroom, V.H.: Work and Motivation. Wiley, New York (1964)

11. East, R., Hammond, K., Wright, M.: The relative incidence of positive and negative word of mouth: A multi-category study. Int. J. Res. Mark. 24(2), 175-184 (2007)

12. Mangold, G.W., Miller, F., Brockway, G.R.: Word-of-mouth communication in the service marketplace. J. Serv. Mark. 13(1), 73-89 (1999)

13. Evanschitzky, H., Gopalkrishnan, R.I., Plassmann, H., Niessing, J., Meffert, H.: The relative strength of affective commitment in securing loyalty in service relationships. J. Bus. Res. 59, 1207-1213 (2006)

14. Hallowell, R.: The relationships of customer satisfaction, customer loyalty and profitability: an empirical study. Int. J. Serv. Ind. Manag. 7(4), 27-42 (2006)

15. Steenkamp, J.B.E.M., Geyskens, I.: How Country Characteristics affect the perceived value of a website. J. Mark. 70(3), 136-150 (2006)

16. Zaichkowsky, J.L.: Measuring the Involvement Construct. J. Consum. Res. 12(4), 341-352 (1985)

17. Lichtenstein, D.R., Netemeyer, R.G., Burton, S.: Distinguishing coupon proneness from value consciousness: an acquisition-transaction utility theory perspective. J. Mark. 54, 54-67 (1990)

18. Nunnally, J.C.: Psychometric Theory, 2nd edn. McGraw-Hill, New York (1978)

19. Nurosis, M.J.: SPSS: Statistical Data Analysis. Spss Inc. (1993)

20. Jöreskog, K., Sörbom, D.: LISREL 8 Structural Equation Modeling with the SIMPLIS Command Language. In: Scientific Software International, Chicago-Illinois (1993)

21. Jöreskog, K.: Statistical analysis of sets of congeneric tests. Psychom. 36(2), 109-133 (1971)

22. Fornell, C., Larcker, D.: Structural Equation Models With Unobserved Variables and Measurement Error. J. Mark. Res. 18, 39-50 (1981)

23. Wiertz, C., De Ruyter, K.: Beyond the Call of Duty: Why Consumers Contribute to Firmhosted Commercial Online Communities. Organ. Stud. 28(3), 347-376 (2007)

24. Murray, K.B., Schlacter, J.L.: The Impact of Services versus Goods on Consumers's Assesment of Perceived Risk and Variability. J. Acad. Mark. Sci. 18(1), 51-65 (1990)

25. Oliver, R.: A Cognitive Model of the Antecedents and Consequences of Satisfaction Decisions. J. Mark. Res. 14, 495-507 (1980)

26. Casaló, L.V., Flavián, C., Guinalíu, M.: The role of satisfaction and website usability in developing customer loyalty and positive word-of-mouth in the e-banking business. Int. J. Bank. Mark. 26(6), 399-417 (2008) 